\title{
Trazos de escritura y política en la filosofía de Simone Weil
}

Aspects of Writing and Politics in the Philosophy of Simone Weil

\author{
Emilse Galvis-Cristancho ${ }^{\star}$ \\ Universidad de los Andes (Colombia)
}

Recibido: 30 de agosto de 2014

Envío a pares: 30 de agosto de 2014

Aprobado por pares: 21 de octubre de 2014

Aceptado: 3 de noviembre de 2014

Pensamiento y Cultura | ISSN: 0123-0999 | eISSN: 2027-5331

pensam.cult | Vol. 18-1 | Junio de 2015 | pp. 132-154

DOI: $10.5294 /$ pecu.2015.18.1.5

• Este artículo hace parte del proyecto de investigación Marx y la democracia, de la Fundación Universidad Autónoma de Colombia del año 2015-2016. le.galvis136@uniandes.edu.co 


\section{Trazos de escritura y política en la filosofía de Simone Weil}

Resumen: este artículo sugiere algunos trazos sobre las dimensiones ética y política de la escritura en la experiencia de trabajo en la fábrica que Simone Weil habría vivido en los años 1934-1935, a la vez que se propone seguir las huellas que ella misma habría trazado para repensar la opresión en relación con los gestos, los ruidos, las miradas y las manifestaciones de la condición obrera. Estos dos registros se enlazan en las reflexiones de Weil sobre la condición obrera en el sentido en el que ella, a partir de una herencia marxista particular, problematiza la opresión en una cierta materialidad tanto del discurso como de los cuerpos que se movilizan en el escenario de la fábrica, cuestión que da a este pensamiento una especificidad relevante en cierta tendencia de la filosofía francesa contemporánea.

Palabras clave: escritura; política; Simone Weil; condición obrera; materialidad.

\section{Aspects of Writing and Politics in the Philosophy of Simone Weil}

Abstract: The article looks at several aspects of the ethical and political dimensions of Simone Weil's writing on her experience as a factory worker in 1934-1935. It also attempts to follow the steps she would have taken to rethink oppression in relation to the gestures, sounds, looks and manifestations of the working condition. These two records are intertwined in Weil's reflections on the plight of workers. Based on a particular Marxist heritage, she problematizes oppression in a certain materiality of both the discourse and the bodies that move about in the scenario of the factory, a question that gives this thinking a relevant specificity in a certain tendency in contemporary French philosophy.

Keywords: Writing; politics; Simone Weil; working conditions; materiality. 
Nada se puede hacer por aquéllos cuyo yo ha muerto, absolutamente nada. Pero nunca se sabe si en un determinado ser humano el yo está totalmente muerto o sólo desvanecido. Si no está totalmente muerto, el amor puede reanimarlo como una inyección, pero sólo el amor completamente puro, sin el menor rastro de condescendencia. Simone Weil

El carácter profuso, sugestivo e inquietante de la filosofía de Simone Weil nos impone de entrada una tarea a la hora de precisar la particularidad de su pensamiento en discusiones más amplias de la filosofía política. En efecto, Simone Weil nunca escribiría una obra sobre filosofía política ni tampoco grandes tratados sistemáticos sobre ética y acción política, porque, como afirma Chavarría, su filosofía, toda ella inclasificable y asistemática, estuvo "acompañada desde siempre por la libre voluntad de no seguir ningún dictado; sin pretensión alguna de iniciar una escuela filosófica" (Chavarría 2006, 155). Sin embargo, sus obras, muchas de ellas de carácter biográfico, personal o experimental, incluso literario, estarían rodeadas de preguntas sobre el sujeto político, la posibilidad de una acción política emancipatoria, el trabajo manual e intelectual, el ser-en-común, la condición obrera, entre muchos otros registros que nos sitúan ante el reto de leer, interpretar y recuperar un pensamiento filosófico poco explorado en el campo de las ciencias humanas; pensamiento que, sin duda, tiene distintos ecos y resonancias con ciertas trayectorias de la filosofía política contemporánea.

Así pues, a la luz de la filosofía de Simone Weil, este artículo tiene como propósito repensar las dimensiones ética y política de la escritura como una práctica específica del lenguaje a partir de su compleja relación con la experiencia de trabajo en la fábrica que Weil habría vivido en los años 1934-1935, a la vez que se propone seguir las huellas que ella misma habría trazado para repensar la opresión en relación con los gestos, los ruidos, las miradas y las manifestaciones de la condición 
obrera. ${ }^{1}$ Estos dos registros se enlazan en las reflexiones de Simone Weil sobre la condición obrera en cuanto el hecho de repensar la dimensión ético-política de la escritura en un sentido amplio implica, como lo veremos, una cierta materialidad tanto del discurso como de los cuerpos que se movilizan en el escenario de la fábrica, cuerpos agotados, ruidos y silencios, movimientos, gestos en los que se ponen en juego distintas manifestaciones de la opresión. En otras palabras, las distintas manifestaciones de la opresión en las que se teje una cierta materialidad de los cuerpos es justamente el lugar en el que es posible repensar una dimensión de la escritura en la que se pone en juego la disociación entre trabajo manual y trabajo intelectual.

Teniendo en cuenta este propósito, veremos que, en primer lugar, Simone Weil se sitúa en una herencia marxista particular que la lleva a problematizar y repensar la opresión a partir de distintas perspectivas que exceden la reducción del marxismo a un cierto mecanicismo o cientificismo que piensa la acción política en una transformación en el régimen de propiedad de las fuerzas productivas. Para Weil la opresión hace parte de un cierto engranaje de la fábrica que se reproduce en los cuerpos, los gestos, las palabras y las distintas manifestaciones de la condición obrera; en segundo lugar, trataremos de poner en escena la particularidad del pensamiento de Simone Weil en cierta tendencia de la filosofía francesa contemporánea, que se ha propuesto

1 En esta instancia también será preciso aclarar que este artículo se propone hacer una relectura de la filosofía de Simone Weil, que tomaría distancia de una interpretación según la cual se puede hacer una clasificación por etapas en su pensamiento. Tal interpretación (Tassin, Petrement) insistiría en que ella habría transitado distintos roles desde su papel como filósofa y profesora, luego su etapa de activista política y su experiencia de la fábrica y, finalmente, su encuentro con el cristianismo. A nuestro modo de ver, esta clasificación no permite reconocer un escenario de intersecciones, cruces y bifurcaciones en el pensamiento de Weil, en el que es posible encontrar diálogos, puentes o vínculos sugerentes en los distintos cambios de registro que ella habría vivido. Ahora, si bien no queremos seguir un orden sucesivo en su pensamiento, tampoco diremos que se puede encontrar una continuidad en sus obras, como si se tratase de una totalidad o una filosofía sistemática; queremos más bien tejer y hacer confluir sus reflexiones sobre el lenguaje, su experiencia de trabajo en la fábrica y la sutileza de su escritura en distintos registros: reflexiones teórico-filosóficas, apuntes de la fábrica (piezas, horas, sensaciones, ordenes), pasajes y fragmentos de sus lecturas, experiencias cotidianas del trabajo, llamados a los obreros, cartas a sus amigos y familiares y otros registros que seguiremos de cerca en esta experiencia. 
repensar una serie de categorías en torno al sujeto político, la ética y al lenguaje y problematizaremos allí una cierta dimensión ética y política de la escritura.

\section{Comprender las causas de la opresión social}

Una de las principales razones de considerar La gravedad y la gracia, texto menor quizá, pero a la vez una de las obras más políticas y llamativas de Simone Weil, tiene que ver con que allí se pone de manifiesto la existencia de una certeza que la habría acompañado durante su corta vida. Tal certeza consistiría en una cierta forma de acción política que le permitiría estar en el lugar en el que la desgracia humana propicie el acceso a la verdad. Así, dice Weil: "Estoy fuera de la verdad" y "Tengo la certeza interior de que esta verdad, si en algún momento se me concede, lo será sólo en el momento en el que yo misma me encuentre físicamente en la desgracia, y en una de las formas extremas de la desgracia presente" (Weil 2007, 165 énfasis mío). ¿En qué consiste esta certeza de la que nos habla Weil? ¿De qué nos habla esta filósofa cuando se refiere a una cierta verdad que solo se le concederá mediante la exposición a la desgracia presente? ¿En qué sentido esta verdad tiene que ver con el hecho de desdibujar la dicotomía entre trabajo manual y trabajo intelectual?²

En principio, diremos que esta verdad de la que nos habla Weil tiene que ver con la necesidad de un cierto comprender que ya aparecía en su trabajo filosófico titulado Reflexiones sobre las causas de la libertad y de

2 Por supuesto, a primera vista, estas preguntas sobre la verdad y la certeza podrían tener una resonancia epistemológica; sin embargo, para Weil estas preguntas hacen parte de una reflexión y una inquietud ético-política que la habría interpelado desde sus años de juventud. En sus viajes en Metro en 1927, donde solía coincidir con algunos obreros, Simone Weil le comenta a su amiga Simone Petrement que le interesan los obreros naturalmente, porque encuentra en ellos no solo un espíritu de justicia que golpea el corazón, sino también porque habitan un espíritu más valeroso que los burgueses. También, en el verano de este año, escribe a su padre: "He estado trabajando una hora en el campo, de forma natural y sin ninguna fatiga. Ya sabes cuánto me gusta este mundo de la granja" [Martinière]. En esos años, sus 18 años, Simone Weil ya cortejaba con la idea de que "el hombre más perfecto, el más auténticamente humano, es el que al mismo tiempo es trabajador manual y pensador" (Petrement 1997, 87). Criterio que, como afirma Carlos Ortega, la acompañaría en su corta vida y sería el móvil que orientaría su obra. 
la opresión social, texto escrito en 1934 y cuya obra es reconocida como el "testamento" político de Weil (Ballester 2006, 116). Allí Simone Weil plantea la necesidad de un comprender no tanto como un ejercicio del entendimiento que por medio de unas ciertas categorías se aproxima a la realidad, tampoco como una mera explicación racional sobre un acontecimiento, sino un comprender que estaría en juego en una relación directa con la experiencia. Para Weil esta certeza, que se constituye en su forma de existencia, tendría que ver justamente con la necesidad decomprender en su inherente materialidad las causas de la libertad y de la opresión social en un momento histórico específico en la Europa de la década de 1930. Así pues, la necesidad de este comprender la llevaría a dar un giro radical en su propia forma de vida en el momento en el que decide abandonar sus clases en la École normale supérieure para trabajar como fresadora en una fábrica de Renault en diciembre de $1935 .^{3}$

Así, cuando Weil escribe un artículo titulado "La huelga de los obreros metalúrgicos" (1936), después de habitar con su cuerpo, su atención y su exposición la experiencia de la fábrica, insistirá en que "cuando se tienen ciertas imágenes clavadas en el alma, en el corazón y en la misma carne, se comprende. Se comprende todo enseguida. No tengo más que dejar fluir los recuerdos" (Weil 2002, 115 énfasis mío). Este comprender insinúa enseguida una suspensión de la primacía del entendimiento sobre la experiencia, un comprender en el que se entrelazan de cierto modo el trabajo intelectual y el trabajo manual. En sus palabras: "Sólo el trabajo manual como factor de equilibrio entre el espíritu y la materia puede hacer consciente la vida [...] de manera que "la civilización más plenamente humana será aquella que tenga al trabajo manual como centro, aquella en la que el trabajo manual constituya el valor supremo" (Weil 2007, 14 énfasis mío). En estas palabras, Weil recoge muy bien la necesidad del trabajo manual en el que es posible

3 Así, en una carta que le escribe a su amigo Nicolas Lazarévitch, a quien había conocido en la Révolution prolétarienne, le confiesa: "He podido llevar a cabo [...] un proyecto que me interesa desde hace años [...] trabajar en una fábrica" (Weil 2010, 56). La Révolution prolétarienne es una revista sindicalista-comunista. Nicolas Lazarévitch se enrola en el Ejército Rojo en 1919, luego toma distancia con respecto al régimen soviético, a partir de 1921. Trabajó en la antigua Unión Soviética como obrero y, sobre todo, como minero. 
comprender la propia existencia. Es decir que el valor supremo del trabajo manual consistiría en una suerte de verdad sobre la existencia del hombre en cuanto allí se puede hacer consciente la vida, en cuanto allí se pueden experimentar las causas de la opresión social en la plena consumación de su materialidad. En este sentido, la necesidad como rasgo de la realidad aparece en la obra de la autora como un modo de experiencia antes que como una cuestión teórica, justamente porque se desestabiliza esta dicotomía entre lo teórico y lo material.

A la luz de esta certeza que acompañaría la vida de Weil y su necesidad de comprender las causas de la opresión social, es necesario reconocer en este punto la herencia marxista en la filosofía de esta pensadora francesa. En Reflexiones..., la filósofa francesa afirma: "La gran idea de Marx es que tanto en la sociedad como en la naturaleza las cosas solo se realizan mediante transformaciones materiales" (Weil 2014, 14). Bajo esta premisa, en palabras del propio Marx, estaría en juego el hecho de que "los hombres hacen su propia historia, pero no la hacen arbitrariamente, en las condiciones escogidas por ellos mismos, sino en condiciones directamente dadas y heredadas del pasado" (Marx 1971 [1852]; Sartre 1960). Para Weil sería justamente Marx quien situaría en la arena política del siglo XIX una manera muy específica de aproximarse al acontecer histórico de su época, según la cual la historia y sus condiciones materiales determinan las formas de organización social, condiciones materiales que estarían directamente dadas y heredadas del pasado. ${ }^{4}$

Esta pregunta por la historia y este método de análisis de las condiciones materiales - que es tan importante y particular para Marx- lo llevaría a tomar como punto de partida en su análisis la forma más simple

4 Así, en oposición a explicaciones ahistóricas de la filosofía hegeliana como producción de ideas y representaciones de la conciencia o de la economía política clásica que considera como inmutables las leyes que rigen las dinámicas sociales, Marx habría puesto en escena una nueva forma de entender la estructura de una sociedad, ya no en una historia lineal y evolutiva en la que se da cuenta de la historia de la humanidad, sino de acuerdo con su acontecer histórico y material. En palabras de Marx: "No es la conciencia la que determina la vida, sino la vida la que determina la conciencia. Desde el primer punto de vista, se parte de la conciencia como del individuo viviente; desde el segundo punto de vista, que es el que corresponde a la vida real, se parte del mismo individuo real viviente y se considera la conciencia solamente como $s u$ conciencia $(2005,26)$. 
del trabajo manual. Así pues, el trabajo ya no sería solo un presupuesto epistemológico concebido como una fuente de riqueza o el trabajo visto exclusivamente en términos cuantitativos, tal y como lo planteaban los economistas clásicos, sino que para Marx el trabajo, en unas condiciones históricas determinadas, sería a la vez, y de manera primordial, un problema político, en el sentido en el que es necesario cuestionarse ¿a quién beneficia este trabajo?, ¿quiénes trabajan?, ¿cómo lo hacen? y ¿por qué lo hacen?, etcétera. ${ }^{5}$ En este sentido, Marx encuentra, y este es un punto que Simone Weil profundizará, que en el fondo del modo de producción capitalista aquellos que venden su fuerza de trabajo lo hacen en condiciones de opresión, explotación y precariedad, que estarían ocultas en las relaciones de intercambio de las mercancías.

A partir de lo anterior, Simone Weil considera necesario "llegar a captar el mecanismo de la opresión, a comprender en virtud de qué surge, subsiste, se transforma, y en virtud de qué podría tal vez desaparecer en teoría" (Weil 2014, 27 énfasis mío). Además, aquello que le interesa a Weil de estas reflexiones es precisamente en virtud de qué podría desaparecer tal opresión. En otras palabras, la pregunta fundamental que rescata Weil de Marx es en virtud de qué podrían llegar a transformarse esas condiciones que responden a una materialidad específica y en virtud de qué podríamos llegar a pensar en una organización social distinta. De manera que, tanto Weil como Marx, estarían planteando una reflexión ético-política sobre la historia, una reflexión filosófica, que sería, en todo caso, distinta de un juicio moral entre buenos y malos, porque precisamente se trata de dar cuenta de unas condiciones materiales e históricas específica. En este sentido, Weil estaría situada en esta cierta tradición del pensamiento filosófico de Marx, que buscaría poner de manifiesto no solo una visión economicista del trabajo, sino el trabajo como obedeciendo a una red y multiplicidad de factores, gestos y manifestaciones de la condición obrera en relación, como veremos más adelante, con la escritura

5 El trabajo para Marx es, ante todo, trabajo concreto, porque se lleva a cabo a partir de unas condiciones objetivas - la naturaleza convertida en materia prima y las máquinas-y de unas condiciones subjetivas - la fuerza de trabajo- que transforman las condiciones objetivas. 
como una práctica específica del lenguaje y la corporalidad. Esto es, el trabajo y la opresión en una materialidad del discurso y de los cuerpos que habitan la condición obrera y que se movilizan y dan lugar a un lenguaje otro con respecto de la precariedad, de la corporalidad, de la opresión. En este punto nos surgen algunos cuestionamientos: ¿cómo está pensando Weil esta materialidad tanto del discurso como de los cuerpos? ¿Cuál es el desplazamiento que transita con respecto a la materialidad, entendida desde el punto de vista de la "producción material”, que el propio Marx analiza? ¿En qué sentido esta materialidad permite repensar las causas y los efectos de la opresión?

Simone Weil reconoce que para el mismo Marx no se puede eliminar la opresión si no se suprimen las causas que la hacen posible. En palabras de Weil:

No se puede suprimir la opresión mientras subsistan las causas que la hacen inevitable, y que dichas causas radican en las condiciones objetivas, es decir materiales, de la organización social. Entonces (para ella, Marx) elaboró una concepción de la opresión ya no como usurpación de un privilegio sino como órgano de una función social (Weil 2014, 27).

Es decir que, si no se destruyen las causas materiales de la organización social, no sería posible suprimir allí y en sí misma la opresión. A partir de esta manera particular de aproximarse a la historia que Marx realiza y del análisis de la opresión como una función social, Simone Weil abre la posibilidad de pensar la opresión en distintos registros de la condición obrera a partir de una mirada y sensibilidad muy singular, mirada que pone en marcha una particular "estética de la atención" mucho más compleja sobre la condición obrera en el momento mismo en el que ella experimenta unos años de trabajo en la fábrica (profundizaremos en este concepto de 'estética' más adelante).

Así pues, en contra de unas ciertas lecturas de la época que insistirían en la plena correspondencia entre el desarrollo de las fuerzas productivas y el camino de la liberación, o que afirman que una vez dada la liberación del hombre, en cuanto factor de producción, sería 
posible para él convertirse en un sujeto político; Simone Weil, siguiendo la pregunta por la historia que el mismo Marx se habría hecho, pondría en escena la necesidad de pensar un proceso de liberación en el que no se admita de antemano o casi implícitamente que las fuerzas productivas poseen algo así como una virtud secreta que haría posible la liberación de la humanidad. En palabras de Weil, "antes incluso de examinar la concepción marxista de las fuerzas productivas, llama la atención el carácter mitológico que dicha concepción presenta en toda la literatura socialista, donde es considerada un postulado" (Weil 2014, 11); precisamente, es de este carácter mitológico de las fuerzas productivas del que ella quiere distanciarse. Weil, además, buscaría distinguir su filosofía de lo que ella llama en su época un "socialismo científico" o lo que ella llama una "cultura de especialistas". En sus propias palabras:

El propio "socialismo científico" se ha convertido en el monopolio de unos pocos y los "intelectuales" tienen por desgracia los mismos privilegios en el movimiento obrero que en la sociedad burguesa. Exactamente igual ocurre en el ámbito político. Marx percibió con claridad que la opresión estatal se basa en la existencia de aparatos de gobierno $[. .$.$] pero estos aparatos permanentes son el efecto inevi-$ table de la separación radical en la que el movimiento obrero reproduce integralmente los vicios de la sociedad burguesa (Weil 2014, 9).

Con esta lectura del "socialismo científico", Weil quiere hacer una crítica justamente a esta cultura de especialistas que reproduce el sometimiento del trabajo intelectual sobre el trabajo manual, división que solo perfeccionaría la opresión en este carácter mitológico de la liberación en el desarrollo de las fuerzas productivas. Dicho de otro modo, para Weil la separación radical entre las funciones de dirección y las funciones de ejecución o la clásica y bastante problemática separación entre las fuerzas intelectuales que intervienen en la producción (trabajo intelectual) y el trabajo manual no hace otra cosa que reproducir lo que el mismo Marx llamó con desdén el socialismo utópico, en el sentido en el que sigue existiendo una completa subordinación de los obreros a aquellos que dirigen. Con esta postura, la filósofa francesa quiso refutar 
a algunos marxistas de su época que pretendieron construir una "revolución" a partir del sueño de la liberación de las fuerzas productivas. ${ }^{6}$

Ante este panorama, Weil se propone comprender las causas de la opresión social a partir de un análisis de la condición obrera en distintos registros y manifestaciones. Análisis que respondería a algo así como una "estética de la atención" sobre las causas de la opresión social al que ella misma se expone en su etapa de trabajo en la fábrica entre diciembre de 1934 y agosto de 1935. Carlos Ortega relata algunas de estas manifestaciones en el diario de fábrica de Weil: sus anotaciones

llenas de números sobre las piezas que ha de taladrar, las chapas que ha de cortar o los cartones que ha de troquelar, las horas que ha de hacer y los cálculos de la prima del destajo o del salario, están salpicadas de reflexiones breves [...] de gran agudeza y realismo, junto a la reseña de los menudos incidentes del trabajo: las piezas estropeadas, las broncas de los encargados y jefes, las pésimas condiciones (el frío helado de los vestuarios, el peligro de las máquinas, etc.) (Ortega 2007, 25).

Entonces, ¿cómo pensar esos gestos, esas miradas, estas manifestaciones que hacen parte de un trabajo monótono, rutinario y a destajo? ¿Qué nos dicen estos cuerpos agotados, estos cuerpos sufrientes que hacen parte de un engranaje indeterminado en la fábrica?

Para Simone Weil, la opresión resulta un nudo mucho más complejo que habría que desatar o desamarrar a partir de aquellas distintas manifestaciones en las que el obrero se siente extraño a sí mismo. Tal extrañeza genera una tensión en el pensamiento de Simone Weil, tensión porque esta atención a la materialidad de la opresión se refiere, por un lado, a lo que Marx llamó enajenación en los Manuscritos del 44, suerte de extrañeza del trabajador con respecto a su trabajo, con el producto de su trabajo, con los otros no trabajadores y extrañeza con respecto a sí mismo, a su

6 Así dice Weil: "Esta religión de las fuerzas productivas en cuyo nombre generaciones enteras de empresarios han aplastado a las masas trabajadoras sin el menor remordimiento constituye asimismo un factor de opresión en el interior del movimiento socialista" (2007, 13). 
condición y a su forma de vida. Aquí Simone Weil estaría sugiriendo algo así como la necesidad de recuperar una cierta identidad perdida del trabajador, una necesidad de arraigo que parece sugerir una identidad obrera y que incluso se propone recuperar una cierta "condición obrera". Por otro lado, como veremos más adelante, su apuesta ético-política tendrá que ver más con una desubjetivación, en el sentido en el que la escritura quiebra la identidad de ese ser obrero y crea momentos de apertura a posibilidades otras de ser o a nuevas formas de existencia o “elevación". Entonces, ¿cómo problematizar esta tensión entre lo que podría ser, por un lado, un llamado a una identidad obrera, y en otros momentos una apuesta ético-política por una pérdida de sí del obrero en el escenario de la fábrica?

Con respecto a la enajenación, por supuesto hay una serie de distinciones entre las reflexiones de Simone Weil y su particular atención a la condición obrera y el análisis de la enajenación en Marx. ${ }^{7}$ Sin embargo, en este punto nos interesa rescatar esta forma de extrañamiento que se evidencia también en el pensamiento de Weil. La opresión para ella haría manifiesta tal extrañeza del obrero sobre sí en distintos gestos, miradas, manifestaciones, que permiten comprender que existen situaciones en las que los obreros actúan en contra de sí mismos o en contra del lugar en el que habitan: extraños a sí mismos por el ruido de una máquina, extraños a sí por el tictac de sus cuerpos en una cadena de producción o por la mirada de los otros obreros. En palabras de Weil:

Todos los ruidos tienen un sentido, todos están ritmados y se fundan sobre una especie de gran respiración del trabajo en común, en la cual se embriaga uno si forma parte de él [...] No existen más que ruidos metálicos, mordeduras en el metal; ruidos que no hablan de naturaleza ni de vida, sino de la actividad seria, sostenida e ininterrumpida del hombre sobre las cosas [...] Las lámparas, las correas y las poleas, los ruidos, la chatarra dura y fría, todo concurre a efectuar la transmutación del hombre en obrero $(2010,106)$.

7 No nos detendremos acá en estas diferencias, pero reconocemos que este es un punto crucial en la investigación. 
Esta cita nos remite de nuevo a las distintas formas de pensar la opresión, porque, acaso ¿en qué sentido esos ruidos metálicos, las poleas, la chatarra fría y dura transformaría al hombre en obrero? ¿Cómo entender allí las causas de la opresión social? Para Weil los ruidos embriagan al hombre, porque para ella es claro que "en ciertos momentos el trabajo es lo suficientemente absorbente para que el pensamiento se mantenga por sí mismo dentro de estos límites" $(2010,110)$. En este sentido, los ruidos harían parte de esa imposibilidad de actuar del obrero que no le permitiría exceder sus funciones y asignaciones, la actividad sostenida del trabajo lo haría ocuparse no más y nada más que de sus haceres. Además, a esta particular atención a los sonidos, Weil agrega una observación sobre el cuerpo:

Ese tic-tac cuya monotonía es insoportable de escuchar durante mucho tiempo, los obreros deben casi reproducirlo con su mismo cuerpo. Este encadenamiento ininterrumpido, por otra parte, tiende a hundir al hombre en un sueño, pero hay que soportar tal monotonía sin dormir. [...] la brutalidad del sistema queda reflejada y hecha sensible por los gestos, las miradas y las palabras de los que están alrededor de uno $(2010,115)$.

Serían, pues, este tictac del cuerpo que los obreros reproducen en una secuencia tras otra ininterrumpida, ese trabajo a destajo, no solo por las piezas que ha de taladrar, sino por la reproducción en serie de su cuerpo: el mismo movimiento de sus manos horas tras horas, los gestos, miradas, palabras que permitirían repensar la opresión ya no como obedeciendo al carácter mitológico de las fuerzas productivas, sino ahí en su misma materialidad y precariedad. El cuerpo agotado, la respiración del trabajo en común, el encadenamiento ininterrumpido y el tiempo de la pesadez abren distintos registros para repensar la opresión, y a la vez nos llevan a reflexionar sobre una cierta estética de la atención que se manifiesta en la agudeza de la escritura de Simone Weil. 


\title{
Escritura y política en la filosofía de Simone Weil
}

\author{
Belleza-arraigo-pacto entre uno mismo \\ y sus propias condiciones de existencia.
}

Simone Weil

Ciertamente, la filosofía política, en especial una cierta tradición de la filosofía francesa contemporánea, se ha propuesto problematizar algunas consideraciones en torno al sujeto, la acción política emancipatoria o el ciudadano que se han establecido en la historia de la filosofía política y que, de cierta manera, siguen vigentes hoy en la forma de una política consensual (Habermas 1998). Estas consideraciones están siendo hoy repensadas en escenarios y caminos inusuales y poco transitados del ser unos con otros, de la acción ética, política, estética y en distintas reflexiones que permiten reconfigurar el espacio político en relación con la corporalidad, la mirada, el lenguaje o la escritura, tal y como se evidencia en la trayectoria filosófica de pensadores, como Jacques Rancière, Michel Foucault o Jacques Derrida. Por supuesto, debemos reconocer que, aunque la filosofía de Simone Weil es inicialmente distante en términos lineales a estos pensadores, debido a que se enmarca en el periodo de entreguerras en la Europa de la década de 1930, su forma de hacer filosofía, sus inquietudes en torno a la ética, la atención, la condición obrera, el lenguaje, la acción política y la ruptura a las clásicas dicotomías entre acción y pensamiento, trabajo manual e intelectual o lenguaje y experiencia la ubican, de cierto modo, en esta tradición de la filosofía política.

En primer lugar, Simone Weil se inscribe en esta tradición de la filosofía, porque sus preocupaciones sobre la condición obrera abren distintos registros inexplorados en relación con una dimensión ética y política de la escritura. En este sentido, sus pensamientos, pensamientos que tal y como ella lo afirma responden a una cierta historicidad que excede su vida y su obra, darían apertura a distintas y sugerentes inquietudes y posibles resonancias con filósofos de esta tradición (veremos más adelante unas posibles resonancias). En segundo lugar, esta pensadora se inscribe de manera novedosa en tal tradición, en el sentido en 
el que sitúa en dichas discusiones una nueva dimensión de la opresión, la precariedad y el sufrimiento de la condición obrera a partir de una herencia marxista particular, que ya vimos en el apartado anterior. En esta tradición, una pregunta inicial es ¿cómo pensar la relación entre escritura, política y condición obrera en el pensamiento filosófico de Simone Weil? o ¿de qué manera repensar las dimensiones ética y política de la escritura como una práctica específica del lenguaje a partir de su compleja relación con la experiencia de trabajo en la fábrica que Weil habría vivido en los años 1934-1935?

Inicialmente, diremos que en esta tradición crítica de la filosofía política, la escritura y el lenguaje no pueden ser para esta pensadora francesa un mero ejercicio intelectual que da cuenta de su experiencia en la fábrica o algo así como una declaración que se propone describir una preocupación social sobre los obreros de la época; para Weil la escritura es una desgarradura de la propia corporalidad que tendría semejanza con lo que Blanchot llama una escritura del desastre, ese "desastre [que] lo arruina todo, dejando todo "como estaba" (Blanchot 2015, 36), lo cual quiere decir que la escritura es un escenario que desdibuja los límites que dividen pensamiento, acción y la certeza de comprender las causas de la opresión social, certeza que, como vimos, la habría acompañado durante toda su vida, no solo "al lado" de los oprimidos, sino entre ellos.

Para situar esta segunda problemática, rescataremos por lo menos dos registros del lenguaje y la escritura en el pensamiento de Simone Weil en relación con su experiencia de la fábrica. Un primer registro tiene que ver con la forma misma de hacer filosofía de Simone Weil. Aquí veremos en qué sentido la escritura para Weil es una narración sensible de la experiencia humana que desdibuja la dicotomía entre reflexión y materialidad y veremos por qué esta disociación de la escritura tiene que ver con una cierta materialidad del discurso y de los cuerpos que se movilizan en el escenario de la fábrica. Tal materialidad se inscribe en una estética de la escritura que, como veremos, estaría asociada a una dimensión ética y política en el pensamiento de Simone Weil. En segundo lugar, la escritura le permite a Simone Weil habitar 
una cierta experiencia de espiritualidad ${ }^{8}$ que estaría asociada con una suerte de poesía del trabajo manual, un modo de vida, una experiencia vital, que se moviliza entre la gracia y la gravedad. Aquí la espiritualidad no se reduce a una experiencia religiosa asociada al cristianismo, sino que tiene que ver con un modo de vida asociado a una cierta plenitud del trabajo manual sin finalidad, el trabajo manual y el esfuerzo como una poesía. Es necesario aclarar que esta noción de 'espiritualidad' resuena claramente con un sentido amplio de espiritualidad en la filosofía de Michel Foucault como un modo de vida particular y una transformación de sí del sujeto y de sus prácticas. Veamos estos dos registros.

En La gravedad y la gracia, Simone Weil vuelve a situar en sus reflexiones la experiencia del trabajo manual en relación con el lenguaje. Así, la filosofía de Weil "se asienta, desde muy temprano, en la firme idea de que pensamiento, acción y lenguaje deben estar en compromiso recíproco con su deseo de verdad" (Verdaguer, 2006 145). ${ }^{9}$ Si el lenguaje es un elemento decisivo en la filosofía de Simone Weil, lo primero que quisiera resaltar como eje de investigación es la estética de la escritura en su pensamiento y en su filosofía; esto es, un cierto manifestarse del lenguaje como desgarradura y la puesta en escena de cuerpos, miradas y expresiones que se cruzan y se superponen en la fábrica, lenguaje como fisura que le permite "relatar" en detalle cada ruido, cada movimiento, cada sentir, cada hendidura o cada gesto de los obreros en la fábrica que evocan directamente el dinamismo de distintos cuerpos que se agencian y movilizan allí. ¿En qué consiste esta estética de la escritura y cómo pensar este lenguaje como quiebre de la división entre trabajo manual e intelectual?

8 Esta noción de 'espiritualidad' también resulta novedosa en el pensamiento de Weil. Esta no se reduce a una experiencia mística asociada al cristianismo, sino que se trata, en sus palabras, de una "espiritualidad del trabajo. El trabajo hace que sintamos de manera agotadora el fenómeno de la finalidad rebotada como una pelota; trabajar para comer, comer para trabajar... Si se considera como un fin una de las dos cosas, separadamente la una de la otra, entonces estamos perdidos. El ciclo contiene la verdad" (2007, 37).

9 En palabras de Verdaguer: "Difícilmente su escritura nos es indiferente: elaborada, analítica, precisa, Simone Weil busca no sólo expresar sino hacerse un lenguaje propio para hacer pública una verdad que se nos muestra muda, muda y escondida como el dolor" (Weil 2006, 144). 
Primero, estética de la escritura quiere decir que el lenguaje es una práctica que manifiesta una cierta corporalidad y materialidad de la fábrica, un lenguaje que suspende las fronteras de la escritura como un mero sistema de signos y que, además, desestabiliza la intencionalidad o voluntad de un sujeto y de su enunciación lingüística en un escenario discursivo. Simone Weil sabe que "la brutalidad del sistema queda reflejada y hecha sensible en los gestos, las miradas y las palabras de los que están alrededor de uno" (Weil, 2010, 173) y, por esto, para ella la escritura es un testimonio sensible de la experiencia humana o una escritura corporal que se respira en la fábrica en el encuentro con otros; esto es, una materialidad del discurso y una materialidad de los cuerpos que habitan la precariedad del trabajo manual y que no se reducen a la intencionalidad de Simone Weil ni como obrera ni como escritora. Por esto mismo, también sus frases son cortas y van al ritmo de la producción y sus anotaciones de la fábrica son pensamientos fragmentarios que exceden las palabras y evocan la complejidad del trabajo manual. Entonces, ¿qué nos dice esta forma singular de la escritura como desgarradura, como dislocación sobre la condición obrera, qué nos dice sobre el análisis de la opresión y cómo pensar la politicidad de esta "escritura corporal”? ¿Cuál es la dimensión ética y política de esta escritura?

La escritura en su dimensión ética se entrelaza con un modo de vida particular de la condición obrera que, por un lado, evoca la materialidad del discurso (piezas que ha de taladrar, pensamientos, cartas, relatos de la fábrica, etcétera); y por otro, una materialidad de los cuerpos que se movilizan en la fábrica (gestos, sufrimientos, miradas, movimientos). La ética, si la definimos en términos generales como un modo de vida, se refiere en la filosofía de Weil a estos cuerpos que se movilizan en la fábrica y que habitan las condiciones de opresión y precariedad generadas por el capitalismo; este es su modo de vida y, por ello, justamente allí se despliega la pregunta por cómo pensar en este escenario de opresión y precariedad otros modos de ser o cómo modular en la propia habitación de la condición obrera nuevas formas de existencia. El registro ético hace énfasis en esta forma de vida de la precariedad en el escenario de la fábrica y en las prácticas cotidianas de estos obreros que habitan una particular forma de opresión escenificada en sus rostros, 
miradas, gestos y palabras. Ahora bien, a esta dimensión ética se suma una dimensión política (cómo vivir con otros y reconfigurar el ser-encomún en un escenario histórico específico). Tal dimensión se anuda directamente con la corporalidad en la medida en que se modula en una experiencia compartida, de unas ciertas formas de vida comunes y de una misma condición obrera. Aquí también, de la mano de una dimensión ética, podemos preguntar ¿cómo reconfigurar el espacio común de la fábrica y el ser con otros en el la condición obrera y cómo modular este escenario en la relación consigo mismo y con los otros?

En segunda instancia, llamamos a la filosofía de Simone Weil una "estética de la escritura", porque pone en escena un lenguaje siempre dislocado, fragmentario, incompleto y contradictorio que evoca con cada palabra la materialidad del hastío o de la precariedad del trabajo manual. En este sentido, su escritura suspende la división entre reflexión y materialidad, división que reproducen los socialistas científicos entre aquellos intelectuales que coordinan y los obreros que ejecutan, tal y como lo vimos en el apartado anterior. En otras palabras, la escritura suspende la división entre trabajo manual e intelectual. Cada palabra no es para ella simplemente una pieza dentro de un sistema de signos, sino que en las palabras se puede sentir esa materialidad, porque justamente no hay una dicotomía entre pensamiento y acción. Además, porque las palabras mismas se pueden ver como una materialidad y porque hay pensamiento también en el gesto (la palabra es material, la corporalidad y gestualidad es pensante y el trabajo intelectual es a la vez trabajo manual). La escritura es un testimonio sensible de la experiencia humana o una escritura corporal que se respira en la fábrica en el encuentro con otros; esto es, una materialidad del discurso y una materialidad de los cuerpos que habitan la precariedad del trabajo manual y que no se reducen a la intencionalidad de Simone Weil ni como obrera ni como escritora. Por esto mismo, también sus frases son cortas y van al ritmo de la producción y sus anotaciones de la fábrica son pensamientos fragmentarios que exceden las palabras y evocan la complejidad del trabajo manual. Entonces, ¿qué nos dice esta forma singular de la escritura como desgarradura, como dislocación sobre la condición obrera, qué nos dice sobre el análisis de la opresión y cómo pensar la politicidad de esta "escritura corporal"? 
Esta forma particular de pensar la escritura sugiere un diálogo interesante con el proyecto de Derrida (2012), que tendría por objeto deconstruir toda una tradición de la metafísica occidental que ha dado una primacía a la voz sobre la escritura o lo que el mismo Derrida llama una metafísica de la presencia "la métaphysique de la présence". Una primera línea de resonancia que podemos mencionar entre la filosofía de S. Weil y Derrida es el sentido amplio de escritura en ambos autores. Para Derrida, la escritura se constituye en una práctica o un ejercicio tanto del lenguaje como del pensamiento, que, debido a su fuerza e intensificación del límite del sentido, suspende, excede y quiebra las fronteras sociales y políticas impuestas por cualquier tipo de normativa institucional (Manrique, 2010). Es decir que la escritura, en cuanto es un ejercicio que excede los límites del lenguaje, suspende y desestabiliza las fronteras de la institución y desestabiliza la identidad y subjetividad de los individuos asociados a esta. En efecto, también la escritura para Simone Weil tendría de cierto modo este potencial de intensificación del límite del sentido que desestabiliza las fijaciones institucionales del trabajo en términos generales. Sin embargo, en su filosofía tendríamos que plantear esta pregunta por la institución en la condición obrera y a la luz de esta dicotomía entre trabajo manual e intelectual. Así pues, ¿cómo pensar esta intensificación del límite del sentido en la filosofía de Simone Weil y cuáles serían allí las fronteras sociopolíticas impuestas por toda normativa, que en el caso de Derrida depende de ciertos sistemas legales históricamente determinados?

En principio, diremos que tal suspensión de toda normativa en Simone Weil se enlaza con la ruptura que produce la escritura de una intencionalidad y transparencia de la voluntad de un sujeto y con la suspensión de un esquema dicotómico y de oposiciones que justamente Simone Weil pone en cuestión: trabajo manual e intelectual, pensamiento y acción, etcétera. En este caso, la escritura se desprende de la intencionalidad de Simone Weil como autora, de su obra y de su biografía. Recordemos que en la "última carta que le escribió al padre Perrin, Simone Weil le pedía que centrara su atención y su caridad, no ya hacia ella, sino hacia sus pensamientos que, eso creía, valían mucho más que ella misma" (Weil 2002, 4). La escritura weiliana quiebra las 
fronteras de una voluntad y se despliega en un escenario de cuerpos obreros que habitan condiciones de opresión y precariedad en la fábrica. De la mano de este sentido amplio de escritura, otra posible resonancia con Derrida es el quiebre a la unicidad del yo o la dislocación de la identidad que produce la escritura y que en este mismo gesto da apertura a nuevos modos de ser. Para Derrida, "esta escritura es la experiencia de un límite del sentido, en virtud del cual el sujeto no puede comprenderse a sí mismo, no puede ser dueño de sí ni dar cuenta de sí" (citado en Manrique 2010, 95). La escritura en la filosofía de Simone Weil, de manera similar a la escritura en Derrida, tiene por objeto desafiar y suspender el orden de sí misma y de la identidad del sujeto para dar apertura a una subjetividad otra o a múltiples subjetividades en un escenario complejo de opresión y precariedad. Desarrollaremos mejor esta ruptura de la identidad en el segundo registro asociado a la espiritualidad.

Un segundo sentido de la escritura para Weil estaría asociado a una cierta experiencia de espiritualidad, que le permitiría movilizar su experiencia de vida en la fábrica entre la gracia y la gravedad. Para Weil dos fuerzas reinan en el universo: luz y gravedad, dos dimensiones que rigen la realidad del hombre y de ahí que para esta filósofa francesa "el [hecho de] adoptar el rango del último ser de la ciudad no es sólo un acto de comunión con la desgracia sino que constituye además un modo de engrandecimiento" (2007, 62 énfasis mío). Es decir que el encuentro con la clase de los "vencidos", que sería para ella una comunión con la gravedad, es a la vez un encuentro con un cierto modo de espiritualidad. Sin embargo, ¿cómo entender esta concepción de espiritualidad? ${ }^{10}$

Lo primero que habría que aclarar es que para Weil la gravedad abre un proceso de impersonalización del yo, en el que se manifiesta, por un

10 Así dice Weil: "Tengo una especie de certeza interior creciente de que hay en mí un depósito de oro puro que es para transmitirlo. Pero la experiencia y la observación de mis contemporáneos me persuade cada vez más de que no hay nadie para recibirlo" (2007, 194). Ella misma estaba segura de que su espiritualidad era una fuerza interior difícil de desentrañar para sus contemporáneos. Podríamos decir que era justamente esa certeza del equilibrio entre la gravedad y la gracia la que quería transmitir, pero no encontraba quien pudiese recibir este conocimiento sobre la experiencia sensible del trabajo manual y, por esta razón, se vio siempre en la necesidad de plasmar su experiencia mediante la escritura. 
lado, un desarraigo de la vida en todas sus dimensiones: social, psicológica y física, pero que a la vez da apertura al acto de la gracia, que le permitiría a Weil liberar el alma y el pensamiento del peso de la gravedad. Allí "la gracia, si bien no puede evitar los efectos de la 'gravedad' y la fuerza, sí logra que esa subordinación a la aplastante necesidad, a la pura impotencia, no corrompa el alma” (Ortega 2007, 4). Aunque inicialmente parece contradictoria esta afirmación según la cual es posible una suerte de elevación en las condiciones de precariedad del capitalismo, Weil considera que justamente esta gravedad es una de las miserias más preciosas dadas al hombre, porque le permite ascender. Ascenso que a nuestro modo de ver tiene que ver con la perdida de sí del sujeto y con la posibilidad de vislumbrar posibilidades otras de ser, lo que nos remite de nuevo a una dimensión ética y política de la escritura. Confesarse el hastío sería una forma de subir, por esto Weil afirma:

Trabajo manual. ¿Por qué no ha habido nunca un mistico obrero o campesino que haya escrito sobre cómo aprovechar el hastío del trabajo? [...] Ese hastío es la carga del tiempo. Confesárselo a sí mismo sin concesiones permite elevarse. El hastío en todas sus formas es una de las miserias más preciosas que le hayan sido dadas al hombre como escala para subir (2007, 207 énfasis mío).

Es de esta manera como Weil introduce en su comprensión de espiritualidad el acto de la escritura como una forma de reconocer la gracia divina, una gracia que se manifiesta en la fábrica misma, en el contacto con el metal frío, con los ruidos o con la opresión en un sentido amplio, en lo que Weil llama la poesía del trabajo manual. Para Simone Weil, esta forma particular de sabiduría y de gracia no sería directamente su ejercicio de escritura, es decir que la escritura no se reduce a una representación de la experiencia o la descripción de un estado de cosas, sino que obedece, como hemos dicho, a unos cuerpos que se movilizan en el escenario de la fábrica o a una estética de la escritura.

La espiritualidad, como un modo de vida, estaría asociada a una cierta plenitud del trabajo manual sin finalidad, el trabajo manual y el esfuerzo como una poesía. En palabras de Weil: "Esfuerzo sin finalidad. 
Es tremendo -y lo más hermoso que hay- cuando la finalidad no tiene fin. Sólo lo bello permite estar satisfecho con lo que existe" (2007, 121). Esta satisfacción con lo que existe, lejos de toda forma de conformismo o derrotismo en la filosofía de Weil, se trata de una "acción como potencia pasiva” (Espósito 1999, 126). Esta interpretación de Espósito sugiere, desde el punto de vista de Weil, que es posible "actuar no por un objetivo, sino a causa de una necesidad [...] No es acción sino una especie de pasividad", que, tal y como lo indica Espósito, es, en todo caso, una potencia de la acción "potencia en la pasividad; pasividad para la potencia" $(1999,126)$.

\section{Referencias bibliográficas}

Acosta, María del Rosario y Manrique, Carlos Andrés. 2013. A la sombra de lo político: violencias institucionales y transformaciones de lo común. Bogotá. Universidad de los Andes.

Ballester, Xavier. 2006. "Realismo frente a utopía”. Revista anthropos: Huellas del conocimiento 211: 114-120.

Blanchot, Maurice. 2015. La escritura del desastre. Madrid: Trotta.

Chavarria Curto, Adrià. 2006. "La fuerza en Simone Weil: “Troya” y "Venecia salvada". Revista anthropos: Huellas del conocimiento 211: $155-162$

Derrida, Jacques. 2012. Espectros de Marx. Madrid: Trotta.

Esposito, Roberto. 1999. ¿Hannah Arendt o Simone Weil? Barcelona: Paidós.

Manrique, Carlos A. 2010. "(Com)partiendo el secreto, entre la ley y la ficción (la literatura y lo político en el pensamiento de Jacques Derrida)". Revista de Estudios Sociales 35: 88-100.

Marx, Karl. 1971. El 18 brumario de Luis Bonaparte. Barcelona: Ariel.

Marx, Karl. 2005. La ideología alemana. Madrid: Losada.

Marx, Karl. 2006. Introducción general a la crítica de la economía política/1857. México: Siglo XXI. 
Marx, Karl. 2008. Escritos de juventud sobre el derecho: textos 1837-1847. Barcelona: Anthropos.

Ortega, Carlos. 2007 “Introducción”, en Simone Weil, La gravedad y la gracia. Madrid: Trotta.

Petrement, Simone. 1997. Vida de Simone Weil. Madrid: Trotta.

Sartre, Jean-Paul. 1963. Crítica de la razón dialéctica. Buenos Aires: Losada.

Tassin, Etiènne. 2012. "De la subjetivación política. Althusser/Rancière/ Foucault/Arendt". Revista de Estudios Sociales 43: 36-49.

Weil, Simone. 2000. Escritos esenciales. Bilbao: Sal Terrae.

Weil, Simone. 2006. "Simone Weil: experiencia del significado del misterio de la existencia". Revista Anthropos.

Weil, Simone. 2007. La gravedad y la gracia. Madrid: Trotta.

Weil, Simone. 2010. La condición obrera. Buenos Aires: El Cuenco de Plata.

Weil, Simone. 2014. Reflexiones sobre las causas de la libertad y de la opresión social. Barcelona: Paidós. 